Lidija P. Pasuljević Shimwell

Univerzitet u Beogradu

UDK 811.133.1'243:371.3(497.11)

Filološki fakultet

DOI: $10.19090 / \mathrm{mv} .2018 .9 .297-317$

Doktorske studije - modul jezik

lidija.pasuljevic@gmail.com

\title{
ISTRAŽIVANJE KOGNITIVNO-AKADEMSKE JEZIČKE SPOSOBNOSTI UČENIKA UKLJUČENIH U SRPSKO-FRANCUSKU CLIL NASTAVU U SRBIJI: ANALIZA REZULTATA TESTIRANJA IZ PREDMETA ISTORIJA NA FRANCUSKOM JEZIKU
}

\begin{abstract}
APSTRAKT: Predmet istraživanja rada je ispitivanje pisane recepcije iz predmeta Istorija na francuskom jeziku među učenicima koji su uključeni u dvojezičnu srpsko-francusku nastavu prema CLIL modelu. Cilj rada je da utvrdimo da li se zahvaljujući CLIL nastavi kod učenika razvija kognitivno-akademska jezička sposobnost (eng. CALP) francuskog jezika. U istraživanju su učestvovali učenici četvrtog razreda dvojezičnih odeljenja iz Treće beogradske gimnazije i Desete gimnazije „Mihajlo Pupin”. Ispitanici su radili test iz predmeta Istorija na francuskom jeziku, koji se sastoji od zadataka vezanih za razumevanje pročitanog teksta i leksiku koja je u njemu upotrebljena. Prilikom analize rezultata primenili smo kvalitativnokvantativnu i deskriptivnu metodu. Rezultati testiranja pokazuju da CLIL nastava daje rezultate, te da učenici na kraju školovanja imaju razvijenu CALP kompetenciju.
\end{abstract}

Ključne reči: dvojezična nastava, CLIL, francuski jezik, istorija, CALP kompetencija, pisana recepcija.

\section{THE RESEARCH OF COGNITIVE ACADEMIC LANGUAGE PROFICIENCY OF STUDENTS INVOLVED IN THE FRENCH CLIL IN SERBIA: ANALYSIS OF RESULTS OF THE HISTORY TEST IN THE FRENCH LANGUAGE}

\begin{abstract}
The topic of the paper is the examination of CLIL students' French language reading comprehension skills in History as a non-language subject. These students are enrolled in bilingual education in Serbian as a native language and French as a foreign language. The goal of the paper is to determine whether the methods applied in the CLIL programme contribute to the development of students' Cognitive Academic Language Proficiency (CALP) in the French language. Fourth-year students of the Third Belgrade High School and the Tenth High School "Mihailo Pupin" participated in our study. Students were given a written test in History, which consists of two parts - questions assessing reading comprehension and vocabulary. When analysing students' achievement in the test, we used the qualitativequantitative and the descriptive methods. The results of the test show that the CLIL programme is effective, showing that students developed CALP.
\end{abstract}

Key words: bilingual education, CLIL, French Language, History, CALP, reading comprehension. 


\section{UVOD}

Bilingvalno ili dvojezično obrazovanje je vid obrazovanja koji se odvija na više od jednog jezika, a često uključuje više od dva jezika (Baker 2001 u García 2009: 6), odnosno ,iziskuje da se nastava nejezičkih predmeta izvodi bar na dva jezika" (Skutnab-Kangas 1991: 145).

CLIL pristup (eng. Content and Language Integrated Learning) predstavlja jedan od mnogobrojnih modela dvojezičnog obrazovanja koji se može primeniti na svim njegovim nivoima, a podrazumeva integrisano učenje jezika i nejezičkog sadržaja. CLIL nastava je organizovana tako da učenici časove jednog ili više nejezičkih predmeta (npr. istorija, biologija, matematika i dr.) delimično ili potpuno prate na stranom jeziku. Taj jezik se naziva vehikolarnim ili posrednim/posredničkim jezikom (eng. vehicular language). Nastavnici koji predaju na stranom jeziku ne moraju biti izvorni govornici tog jezika.

Ovaj model posebno podržava Evropska komisija u okviru svoje politike višejezičnosti. U cilju širenja višejezičnosti i ostvarivanja formule „maternji jezik plus još dva jezika" (eng. MT+2 formula), Evropska komisija i Savet Evrope podržali su implementaciju CLIL-a, jer odgovara navedenim potrebama (Marsh 2002: 11). Zahvaljujući integrisanom učenju stranog jezika i sadržaja, ovim programom se otvara mogućnost za uvođenje novih jezika u školske programe, pošto se nastava nejezičkih predmeta odvija na tim jezicima, te ne postoji potreba za dodatnim fondom časova (Wolff 2002: 47).

Nekoliko glavnih ciljeva CLIL pristupa su: (1) edukovanje pojedinaca na dva jezika čime oni stiču društveno prikladnu i svrsishodnu upotrebu jezika, to jest znanje kako se jezik efektivno upotrebljava, a ne znanje o jeziku (Vučo 2014: 113); (2) usvajanje nejezičkog sadržaja; (3) jačanje samopouzdanja učenika na oba jezika koja su prisutna u nastavi; (4) razvoj sposobnosti razmišljanja kod učenika (eng. thinking skills); (5) podsticanje opštih društvenih i nacionalnih vrednosti među učenicima (Bentley 2010: 6 u Zavišin 2011: 734).

\section{USVAJANJE STRANOG JEZIKA U OKVIRU CLIL PRISTUPA}

Brojne studije pokazuju pozitivan uticaj CLIL pristupa na usvajanje stranog jezika na kojem se izvodi nastava (v. Admiraal, Westhoff, \& de Bot 2006; Lasagabaster 2008; Lorenzo et al. 2005; Ruiz de Zarobe 2008, 2010; Zavišin 2013). faktora.

$\mathrm{Na}$ proces učenja stranog jezika u kontekstu CLIL-a utiču dva glavna

Prvi faktor je kvantitativne prirode i vezan je za dužinu izlaganja posredničkom jeziku. CLIL učenici su izloženi stranom jeziku više sati od njihovih vršnjaka koji ga uče u okviru tradicionalne nastave stranog jezika, budući da uz redovne časove stranog jezika, prate nastavu nejezičkog predmeta na istom jeziku. Broj sati koji CLIL učenici provedu uronjeni u strani jezik može biti dupliran u odnosu na tradicionalnu nastavu. 
Drugi faktor je kvalitativnog karaktera i, čak, u većoj meri pomaže učenicima da bolje savladaju strani jezik. Naime, strani jezik u funkciji posredničkog jezika na časovima nejezičke discipline nije samom sebi cilj, već je instrument za usvajanje drugih sadržaja i veština. Ovakav kontekst učenja stranog jezika u autentičnom ambijentu sličan je stvarnom životu i prirodnom načinu usvajanja prvog jezika. Iz tog razloga možemo reći da učenje stranog jezika u CLIL-u pre odgovara konceptu usvajanja jezika (eng. language acquisition) nego učenju jezika (eng. language learning) (Ellis 2003: 16). Ovako organizovana nastava odgovara i Krešenovoj teoriji o usvajanju drugog jezika (eng. Second Language Acquisition) i ,pravilu zaborava” (eng. Forgetting Hypothesis), prema kojima se jezik lakše uči ukoliko učenik nije svestan da to čini, već jezik koristi spontano (Vučo 2006: 42).

U CLIL nastavi razlikujemo tri aspekta stranog kao posredničkog jezika. Ovaj koncept je poznatiji kao ,jezički triptih” (eng. Language Triptych). On povezuje ciljeve nastave vezane za jezik i sadržaj (Coyle et al. 2010: 36-37):

- Jezik učenja (eng. language of learning) obuhvata analizu lingvističkih znanja koja su učenicima potrebna kako bi raspolagali osnovnim znanjima i veštinama vezanim za sadržaj nejezičkog predmeta; radi se o stručnom jeziku specifičnom za nejezičku disciplinu.

- Jezik za učenje (eng. language for learning) je potreban kako bi učenici mogli da rade u sredini u kojoj se koristi strani jezik; oni treba da nauče kako da se služe stranim jezikom u cilju postavljanja pitanja, davanja opisa, izražavanja mišljenja, rada u parovima i sl.

- Jezik kroz učenje (eng. language through learning) podrazumeva aktivnu povezanost jezika i mišljenja bez koje nema efikasnog usvajanja gradiva; nivo učenja se produbljuje kada se od učenika traži da iznesu svoje mišljenje; jezik se stvara i nadograđuje kroz usmeno izražavanje, dijaloške i interaktivne zadatke tokom nastave.

Kako bi se obezbedio napredak u znanjima jezika i sadržaja u CLIL nastavi važno je da se ova tri jezička aspekta ravnopravno razvijaju.

Takođe, budući da CLIL učenici prate nastavu nejezičkih predmeta na stranom jeziku, oni, pored osnovne veštine interpersonalne komunikacije (eng. Basic Interpersonal Communicative Skills - BICS), razvijaju i kognitivnoakademsku jezičku sposobnost (eng. Cognitive Academic Language Proficiency $C A L P)$, koja podrazumeva poznavanje stručnih registara i apstraktnih pojmova. BICS podrazumeva konverzacijsku fluentnost jezika, dok se CALP odnosi na učenikovu sposobnost da razume i izrazi kako usmeno, tako i pismeno, koncepte i ideje koji su relevantni za uspeh u školi (Cummins 2008: 71).

BICS veštine pojedinac koristi, pre svega, u neformalnom kontekstu svakodnevnog života, u situacijama koje nisu kognitivno zahtevne i u kojima se može osloniti na kontekstualne pojedinosti kako bi tumačio poruku (npr. 
gestikulacija sagovornika, izraz lica, ilustracije), što znači da razumevanje poruke ne zavisi isključivo od verbalnog dela poruke (Skutnab-Kangas 1991: 133).

CALP podrazumeva razumevanje i upotrebu specifične terminologije, sinonima, analogija, stručnih registara, apstraktnih pojmova i ideja koji su vezani za jezik različitih nastavnih predmeta, kao i poznavanje i razumevanje funkcionalnog stila udžbeničke literature (Vučo 2009: 246). Kontekstualne pojedinosti koje pomažu u primanju i tumačenju poruke su umanjene ili nepostojeće, a input dolazi od nastavnika ili iz udžbenika (Dale, van der Es \& Tanner 2011: 46). CALP se može shvatiti kao kognitivni instrument u situacijama sa visokim kognitivnim zahtevima, ali u kojima kontekstualne pojedinosti ne mogu mnogo pomoći (Skutnab-Kangas 1991: 134).

\section{CLIL NASTAVA U SRBIJI}

Ministarstvo prosvete je 2000. godine, uz pomoć Svetske banke i Saveta Evrope, započelo projekat osavremenjivanja obrazovnog sistema u Srbiji, koji je uključivao i modernizaciju kurikuluma za strane jezike (Filipović, Vučo \& Đurić 2007: 235). Novi okvir za nastavni program stranih jezika imao je za cilj da: (1) stavi učenika u središte nastave; (2) uvede bar dva strana jezika tokom dvanaest godina osnovnog i srednjeg obrazovanja; (3) ponudi tri ili više jezika kao izborne predmete; (4) postavi ulazni i izlazni nivo jezika učenika prema Zajedničkom evropskom referentnom okviru za žive jezike (ZEROJ) i (5) uvede dvojezičnu nastavu na nivou osnovne i srednje škole (Ibidem).

Dvojezična nastava uvedena je školske 2004/05. godine na italijanskom i francuskom jeziku u Trećoj beogradskoj gimnaziji i na francuskom jeziku u OOŠ „Vladislav Ribnikar” u Beogradu.

Kao ciljevi pojekta dvojezične nastave definisani su - doprinos razvoju višejezičnosti u obrazovnom sistemu Srbije, podizanje nivoa i kvaliteta jezičke kompetencije učenika iz stranog jezika, poboljšanje nivoa nastavničke kompetencije i modernizacija obrazovno-vaspitnog rada kroz uvođenje savremenih i efikasnijih metoda rada (Đurić 2006: 32).

Do kraja 2015. godine nije postojao poseban pravilnik koji reguliše program dvojezične nastave na stranom jeziku, te se nastava sprovodila u skladu sa opštim zakonima o obrazovanju. Pravilnik o bližim uslovima za ostvarivanje dvojezične nastave usvojen je 18. decembra 2015. godine ${ }^{1}$.

Pravilnikom je propisano da CLIL nastava može da se realizuje u prvom, šestom ili sedmom razredu osnovne škole ili u prvom razredu srednje škole. Učenici prvog razreda osnovne škole, koji žele da učestvuju u programu, ne moraju da

${ }^{1}$ Uvid u kritičku analizu Pravilnika moguć je putem sledeće reference: Vučo, J., Begović, A. (2017). „Bilingual Education in Serbia: Models and Perspectives”, u Manjinski jezici u obrazovanju $i$ učenje jezika: izazovi $i$ nove perspektive, prir. J. Filipović \& J. Vučo (Beograd: Filološki fakultet): 225-238. 
dokažu poznavanje stranog jezika, dok se za učenike viših razreda osnovne škole i prvog razreda gimnazije moraju organizovati ispiti za proveru jezičkog nivoa (za šesti razred A1.1, za sedmi razred A1.2 i za prvi razred srednje škole A2 nivo prema ZEROJ-u). Na ispitu se proveravaju četiri jezičke veštine (čitanje, slušanje, pisanje i govor).

U skladu sa zakonskim okvirom, dvojezična nastava se ostvaruje na osnovu postojećeg nastavnog plana i programa za osnovnu i srednju školu koji propisuje Ministarstvo prosvete, nauke $\mathrm{i}$ tehnološkog razvoja ${ }^{2}$. To često podrazumeva da se $\mathrm{u}$ nastavi nejezičkih predmeta koriste domaći udžbenici koji se kombinuju sa dodatnim nastavnim materijalom na stranom jeziku.

Propisano je da se bilingvalna nastava izvodi iz određenih predmeta na stranom jeziku po CLIL pristupu, i to u obimu od minimalno $30 \%$, a maksimalno $45 \%$ od ukupnog godišnjeg fonda časova tih predmeta, ne računajući nastavu iz predmeta Strani jezik. U praksi, nastavnici nejezičkih predmeta odlučuju koje će nastavne jedinice i u kom procentu biti obrađivane na stranom jeziku.

Prema Pravilniku, dvojezičnu nastavu može da realizuje strani lektor, predmetni nastavnik koji se školovao na stranom jeziku na kojem se izvodi dvojezična nastava, predmetni nastavnik čije je znanje stranog jezika tokom prve školske godine realizacije nastave najmanje na B2 nivou prema ZEROJ-u (sa obavezom da u narednih pet godina uz kontinuirano usavršavanje dostigne nivo jezika C1) ili predmetni nastavnik (sa znanjem jezika na B1 nivou) u tandemu sa nastavnikom stranog jezika.

\subsection{Dvojezična nastava u Srbiji školske 2017/18. godine}

Kao što smo pomenuli u prethodnom odeljku, na početku realizacije bilingvalne nastave u Republici Srbiji 2004/05. godine, u projektu su učestvovale jedna osnovna i jedna srednja škola iz Beograda.

U školskoj 2017/18. godini dvojezična nastava se odvija u četrnaest osnovnih i šesnaest srednjih škola - na francuskom, italijanskom, engleskom, nemačkom, ruskom, mađarskom i hrvatskom jeziku. ${ }^{3}$ Ovaj vid nastave prisutan je širom Srbije - u Beogradu, Novom Sadu, Sremskim Karlovcima, Valjevu, Nišu, Pirotu, Sremskoj Mitrovici, Senti, Aleksincu, Gornjem Milanovcu, Subotici, Tavankutu, Vrbasu i Pančevu".

Kada je reč o srpsko-francuskom modelu, CLIL nastavu na francuskom jeziku pohađaju učenici OOŠ „Vladislav Ribnikar”, na nivou osnovne škole, kao i

${ }^{2} \mathrm{Za}$ informacije o nastavnim planovima i programima različitih profila obrazovanja konsultovati: http://zuov.gov.rs/nastavni-planovi-i-programi/ (sajtu pristupljeno 19.11.2015)

${ }^{3}$ Podaci Ministarstva prosvete, nauke i tehnološkog razvoja; podatke nam je ljubazno ustupila Tatjana Jovanović iz Sektora za razvoj i visoko obrazovanje.

${ }^{4}$ Podaci Ministarstva prosvete, nauke i tehnološkog razvoja, koje nam je ljubazno ustupila Tatjana Jovanović iz Sektora za razvoj i visoko obrazovanje. 
učenici Treće beogradske gimnazije, Desete gimnazije „Mihajlo Pupin”, Karlovačke gimnazije, Valjevske gimnazije, Gimnazije „Pirot”, Gimnazije „Svetozar Marković” iz Niša i Gimnazije „Jovan Jovanović Zmaj” iz Novog Sada, na nivou srednje škole.

Na nivou osnovne škole, dvojezična srpsko-francuska nastava odvija se u 7. i 8. razredu, dok se u srednjim školama nastava izvodi od 1. do 4. razreda, i to na opštem, društveno-jezičkom, prirodno-matematičkom i filološkom smeru.

\section{TESTIRANJE KOGNITIVNO-AKADEMSKE JEZIČKE KOMPETENCIJE UČENIKA UKLJUČENIH U CLIL NASTAVU NA FRANCUSKOM JEZIKU}

\subsection{Cilj, hipoteza, predmet i uzorak istraživanja}

Glavni cilj našeg istraživanja jeste da utvrdimo kakav uticaj CLIL pristup ima na usvajanje francuskog kao stranog jezika, to jest da li bilingvalni učenici vladaju kognitivno-akademskom jezičkom sposobnošću (CALP).

Odabrali smo da testiramo učenike na kraju srednjeg obrazovanja, kada možemo sagledati krajnje domete CLIL programa.

Istraživanje je sprovedeno na teritoriji grada Beograda, $u$ dve gimnazije $u$ kojima se sprovodi ovaj vid obrazovanja. U studiji je učestvovalo ukupno 34 ispitanika četvrtog razreda - 19 učenika iz Treće beogradske gimnazije i 15 učenika Desete gimnazije „Mihajlo Pupin”.

Odlučili smo da vladanje CALP kompetencijom ispitamo iz predmeta Istorija, čiju nastavu učenici obe gimnazije zvanično prate na srpskom i francuskom jeziku.

Budući da autori navode da se najbolji rezultati u nastavi stranih jezika postižu u jezičkoj veštini kojoj se tokom nastave posveti najviše pažnje (Petrović 1988: 25), a da se od učenika u CLIL nastavi pre svega traži da poseduju znanje iz receptivnih veština zbog konteksta učenja stranog jezika (Vučo 2007: 267), odlučili smo da predmet našeg istraživanja bude veština razumevanja čitanjem (pisana recepcija).

Pošli smo od pretpostavke da će bilingvalni učenici sa uspehom rešiti naš test pisane recepcije iz istorije na francuskom jeziku, upravo imajući u vidu da učenici CLIL programa delimično prate nastavu istorije na francuskom jeziku, te da na časovima često obrađuju stručne tekstove iz ove oblasti, kao i da usvajaju vokabular specifičan za ovaj nejezički predmet na francuskom jeziku.

\subsection{Tehnike i metode istraživanja}

Za potrebe ovog istraživanja koristili smo tehniku testiranja. Na osnovu gradiva sa kojim su učenici prethodno upoznati na časovima istorije, odabrali smo 
autentičan tekst na francuskom jeziku i sastavili zadatke u vezi sa istim ${ }^{5}$. Tekst nosi naslov Un âge d'or colonial? i preuzet je iz zvaničnog francuskog udžbenika za srednju školu.

Tekst govori o kolonijalizmu sa početka XX veka i podeljen je na tri tematske celine - prva se bavi političkim uređenjem u kolonijama, druga govori o stavu evropskih naroda o kolonijalizmu sa početka prošlog veka, dok treća celina razmatra posledice kolonijalizma za narod koji živi u kolonijama.

Pošto pročitaju tekst, učenici se susreću sa 10 pitanja koja ukupno nose 22 poena. Pitanja su podeljena na dve celine - prvi set pitanja je u vezi sa pročitanim tekstom, a drugi je posvećen stručnim terminima koji su upotrebljeni u tekstu. $\mathrm{Na}$ pitanjima o sadržaju pročitanog teksta ispitanici mogu da osvoje ukupno 12 poena, a na pitanjima vezanim za leksiku 10 poena.

Test se sastoji iz zatvorenih pitanja (višestruki izbor, alternativni izbor, sparivanje) i otvorenih pitanja (kratak ili produženi odgovor, sređivanje zadatih reči u novom kontekstu).

Prilikom interpretacije rezultata testiranja služili smo se kvalitativnom i kvantitativnom (statističkom) metodom, dok smo deskriptivnu metodu koristili prilikom analize otvorenih odgovora ispitanika i u cilju donošenja zaključaka o uzročno-posledičnim vezama između CLIL nastave i rezultata zabeleženih na testu.

Skala koju ćemo primenjivati prilikom prikazivanja uspeha ispitanika je sledeća:

1. Nezadovoljavajući: $0-50 \%$ tačno rešenog testa

2. Minimalno zadovoljavajući: $51-60 \%$ tačno rešenog testa

3. Dovoljan: $61-70 \%$ tačno rešenog testa

4. Dobar: $71-80 \%$ tačno rešenog testa

5. Vrlo dobar: $81-90 \%$ tačno rešenog testa

6. Odličan: $91-100 \%$ tačno rešenog testa

Takođe, u cilju što objektivnije analize rezultata, vodićemo računa i o različitom jezičkom profilu ispitanika. $\mathrm{Na}$ osnovu podataka sakupljenih u anketi koju smo sproveli pre testiranja među učenicima, mogli smo da izdvojimo pet varijabli:

1. „Ribnikar” - učenici koji dolaze iz OOŠ „Vladislav Ribnikar” i uče francuski jezik od prvog razreda.

2. „Ostale škole” - učenici koji su završili ostale osnovne škole.

3. „Ostale škole i časovi” - učenici koji nisu završili OOŠ „Vladislav Ribnikar", a sada uče francuski jezik i u vannastavnom kontekstu pri nekoj

${ }^{5}$ Prilog br. 1. 
školi stranih jezika ili u formi privatnih časova jednom, dvaput ili triput nedeljno.

4. „Ostale škole i boravak” - učenici koji nisu završili OOŠ ,Vladislav Ribnikar", a proveli su određeni životni period na frankofonom govornom području. Ovde ćemo svrstati učenike koji su boravili ili se školovali u frankofonim zemljama u periodu od tri meseca i duže.

5. „Ribnikar i časovi” - učenici koji pored završene OOŠ ,Vladislav Ribnikar" sada uče francuski jezik i u vannastavnom kontekstu pri nekoj školi stranih jezika ili u formi privatnih časova jednom, dvaput ili triput nedeljno.

\subsection{Rezultati testiranja}

$\mathrm{Na}$ osnovu rezultata testiranja, $70,6 \%$ ispitanika postiglo je pozitivan rezultat na testu, tačno rešivši preko $50 \%$ pitanja. Učenici su postigli dovoljan uspeh sa 13,6 prosečnih poena od mogućih 22.

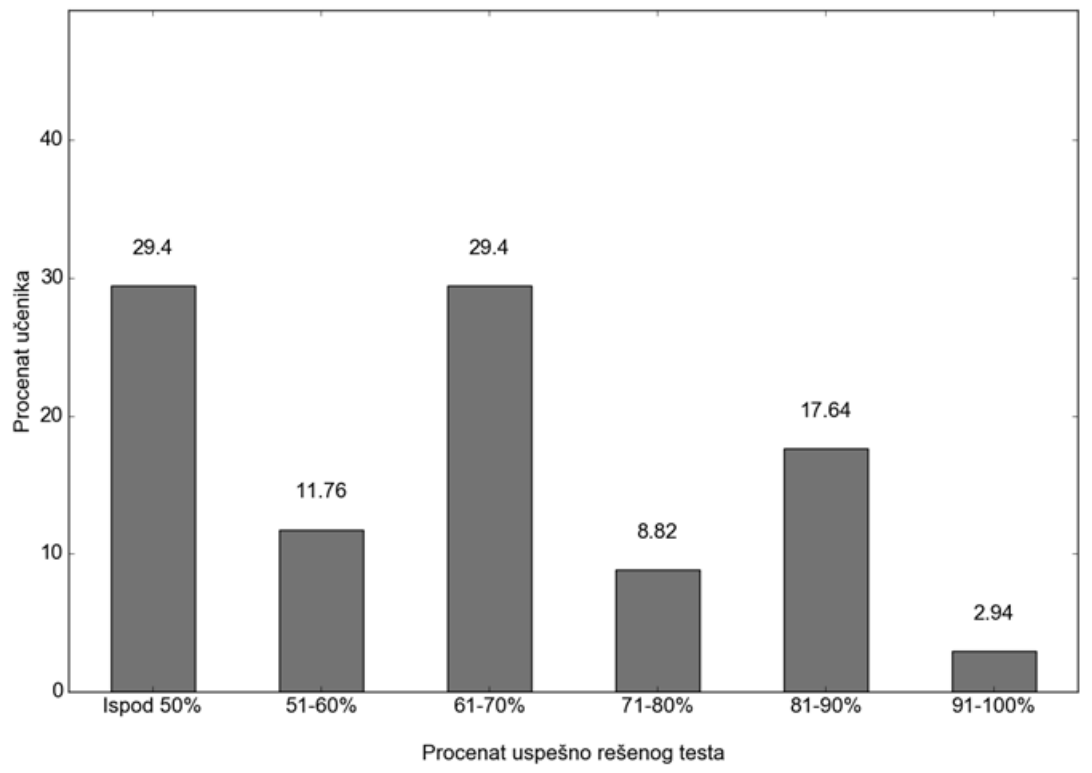

Grafikon 1. Postignuće ispitanika na testu

Najveći broj ispitanika (po 29,4\%) postigao je nezadovoljavajući i dovoljan uspeh, zatim su na drugom mestu ispitanici sa vrlo dobrim uspehom $(17,64 \%)$, potom sa minimalno zadovoljavajućim rezultatom $(11,76 \%)$, dobrim rezultatom $(8,82 \%)$ i najzad, učenici sa odličnim uspehom $(2,94 \%)$.

Minimalan broj poena na testu bio je 4 poena, što predstavlja svega $18,18 \%$ tačno rešenog testa i nezadovoljavajući uspeh. Najbolji rezultat od 21 poena i odličan uspeh na testu ostvarila je učenica koja je završila OOŠ „Vladislav 
Ribnikar", ima položen ispit B2 nivoa francuskog jezika i pohađa privatne časove francuskog jezika.

Faktori koji su pozitivno uticali na postignuće ispitanika su završena OOŠ „Vladislav Ribnikar”, učenje francuskog jezika u vannastavnom kontekstu i boravak u nekoj frankofonoj državi. Postignuće ispitanika na testu u odnosu na pet izdvojenih varijabli prikazano je na Grafikonu br. 2.

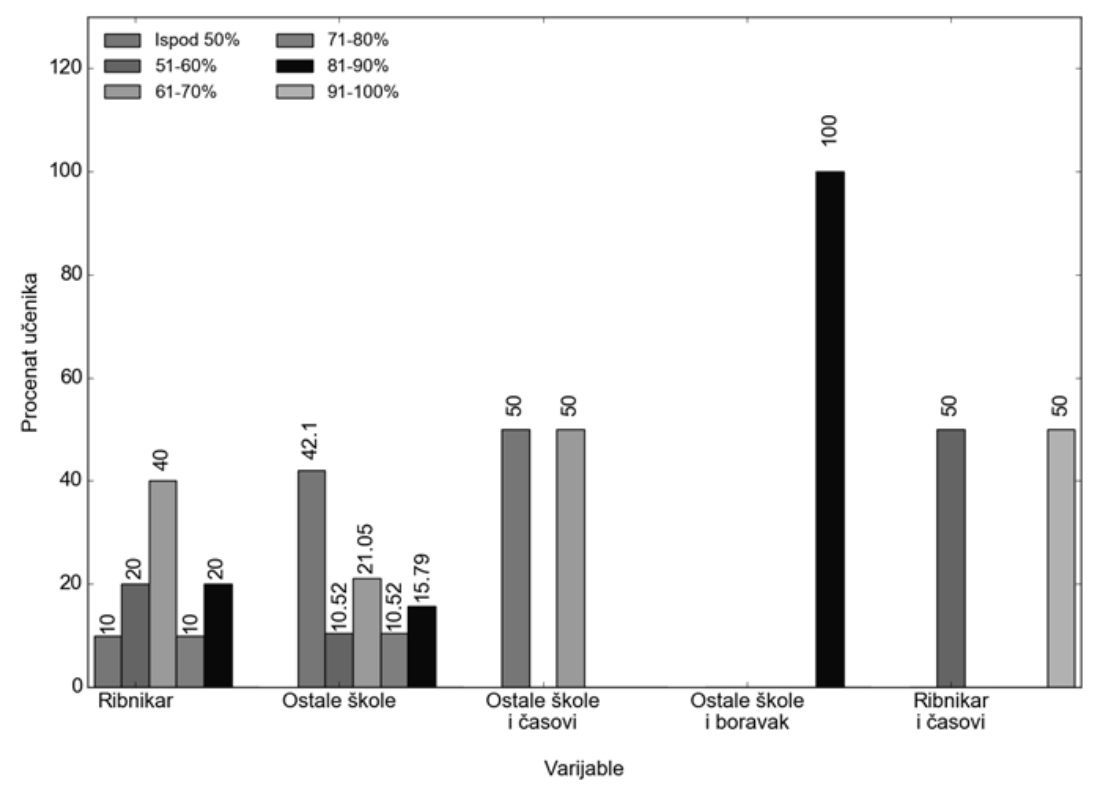

Grafikon 2. Postignuce ispitanika na testu u odnosu na pet izdvojenih varijabli

U prvoj podgrupi ispitanici su postigli od nezadovoljavajućeg do vrlo dobrog uspeha, a u najvećem procentu dovoljan uspeh (40\%). U drugoj podgrupi je takođe bilo učenika sa rezultatom od nezadovoljavajućeg do vrlo dobrog uspeha, a najbrojniji su bili oni sa nezadovoljavajućim uspehom (42,1\%). U podgrupi „Ostale škole i časovi" polovina ispitanika je postigla nezadovoljavajući rezultat, a polovina dovoljan uspeh. Učenica koja je boravila u inostranstvu osvojila je vrlo dobar uspeh. Na kraju, ispitanici koji su završili OOŠ „Vladislav Ribnikar”, a pohađaju časove francuskog jezika van redovne školske nastave, su osvojili u jednakom broju minimalno zadovoljavajući i odličan rezultat (po 50\%).

$\mathrm{Na}$ osnovu poslednje podgrupe možemo videti da je postignuće na testu umnogome zavisilo od individualnih sposobnosti učenika da primene stečena znanja, kao i od lične motivacije prilikom izrade testa.

Budući da je samo na osnovu grafikona teško zaključiti koja varijabla je najviše uticala na uspešno rešavanje testa i bolji uspeh na testu, uporedićemo ukupan procenat tačno rešenog testa po varijablama.

Ispitanici na koje se odnosi varijabla „Ostale škole i časovi” tačno su rešili $50 \%$ testa, ispitanici iz podgrupe „Ribnikar” tačno su rešili $67,05 \%$ testa, zatim su 
ispitanici iz podgrupe „Ostale škole” rešili 57,64\% testa, „Ribnikar i časovi” $77,27 \%$ testa i najzad, sa 86,36\% tačnih odogovora, najuspešnija je bila učenica koja je boravila u inostranstvu.

Dakle, kao ključni faktor postignuća na testu, izdvojio se boravak na frankofonom području. Ovo je očekivani podatak, budući da je učenica iz ove podgrupe duži period boravila u Kanadi, tokom kojeg je bila uronjena u francuski jezik, a na njemu se i školovala.

Kada analiziramo postignuće ispitanika na dva odvojena dela testa, učenici su se pokazali uspešnijim na pitanjima vezanim za razumevanje čitanjem. Naime, oni su tačno rešili $70,22 \%$ pitanja na prvom delu testa sa prosečno 8,4 poena od mogućih 12. Sa druge strane, ispitanici su tačno rešili 52,06\% pitanja o stručnim terminima, zabeleživši ukupno 5,2 od mogućih 10 poena.

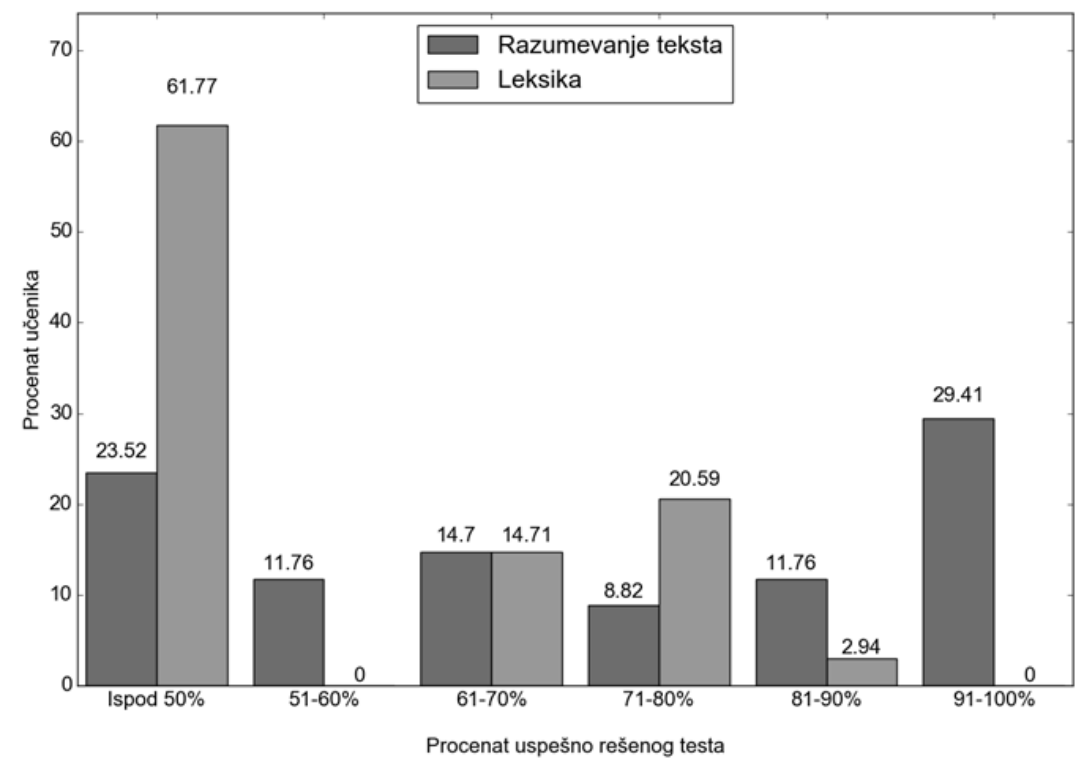

Grafikon 3. Poređenje postignuća ispitanika na zadacima koji se odnose na pisanu recepciju i leksiku

Kako vidimo na Grafikonu br. 3, najveći procenat učenika je na prvom delu testa postigao odličan uspeh $(29,41 \%)$, a na drugom delu nezadovoljavajući uspeh $(61,77 \%)$. Na prvom delu testa bilo je najmanje ispitanika sa dobrim rezultatom $(8,82 \%)$, a na zadacima o leksici sa vrlo dobrim uspehom $(2,94 \%)$.

Budući da su ispitanici tačno rešili preko polovine zadataka o pisanoj recepciji, kao i da su u najvećem procentu zabeležili odličan uspeh, možemo zaključiti da su CLIL učenici četvrtog razreda dve beogradske gimnazije uspešno rešili test. 
Stoga možemo reći da ovaj vid nastave pokazuje pozitivan uticaj na savladavanje veštine razumevanja čitanjem stručnog teksta iz istorije na francuskom jeziku, kao i na razvoj CALP kompetencije iz ove oblasti.

Takođe, CLIL nastava iz istorije u Trećoj beogradskoj gimnaziji i Desetoj gimnaziji „Mihajlo Pupin” pozitivno utiče na usvajanje stručnih termina na francuskom jeziku, iako ne u jednakoj meri, jer su ispitanici na ovom delu testa tačno rešili više od polovine zadataka, ali sa minimalno zadovoljavajućim uspehom.

Navedenu činjenicu dokazuje i Grafikon br. 4 koji prikazuje najčešće greške učenika.

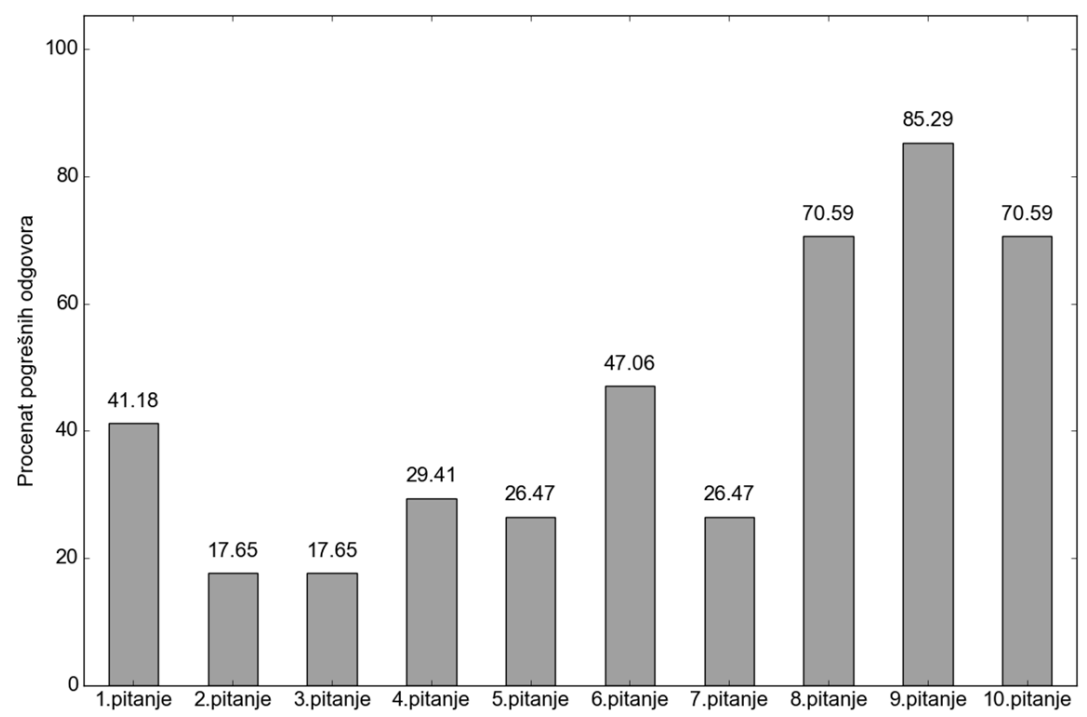

Grafikon 4. Procenat netačnih odgovora po pitanjima

Ispitanici su upravo postigli manji procenat grešaka, i to ispod $50 \%$, od 1 . pitanja zaključno sa 7. pitanjem, koja se odnose na pročitani tekst. Preko $50 \%$ grešaka bilo je od 8. do 10. pitanja, koja su se upravo odnosila na definisanje $\mathrm{i}$ pronalaženje sinonima za termine iz pisanog teksta.

Najmanji broj grešaka (po 17,65\%) zabeležili smo u 2. i 3. pitanju zatvorenog tipa. U 2. pitanju se od kandidata očekivalo da označe cilj teksta među četiri ponuđena odgovora, dok se u trećem pitanju tražilo da označe opis koji najbolje odgovara kolonijalnom sistemu sa kraja XIX i početka XX veka.

Najveći procenat pogrešnih odgovora dvojezični ispitanici su zabeležili u 9. zadatku $(85,29 \%)$. U ovom zadatku se od učenika očekivalo da među ponuđenim odgovorima označe sinonime koji bi najbolje zamenili tri reči iz teksta u skladu sa kontekstom u kojem su upotrebljeni u tekstu.

U nastavku ćemo analizirati odgovore ispitanika na dva otvorena pitanja na testu $-\mathrm{u}$ 7. pitanju iz prvog segmenta i u 10. pitanju iz drugog segmenta testa. 
Na osnovu kvalitativnog tumačenja odgovora, možemo doneti zaključke o načinu na koji se učenici služe francuskim jezikom.

U 7. pitanju produženog odgovora, ispitanici su imali prilike da iznesu svoj stav o kolonijalnom sistemu, i to na osnovu podataka koje su dobili u tekstu. Ovaj zadatak nam omogućuje da, pored analize pisane recepcije, koja je glavni predmet našeg istraživanja, tumačimo i kratku pisanu produkciju učenika.

U zavisnosti od toga da li su ispitanici odgovorili na temu i kako vladaju gramatičkom kompetencijom, mogli su da osvoje od 0 do 3 poena $(1,5$ poen za primerenost odgovora - razumevanje teme i koherentnost odgovora; 1,5 poen za jezičku tačnost - morfosintaksa i izbor rečnika).

U zadacima smo uočili najviše morfosintaksičkih grešaka, zatim pravopisnih grešaka i omaški, a najmanje leksičkih grešaka. U nastavku ćemo navesti i tumačiti nekoliko upečatljivih primera.

Učenica iz podgrupe „Ribnikar” i sa 90,91\% tačnih odgovora je napisala:

Je suis contre la colonialisation, parce que ça aide au detruiment culturelle des populations locales. Les pays qui ont les colonies ont une grande influence sur la qualité de vie dans les colonies.

Ovo je primer dobrog odgovora, budući da je učenica odgovorila na temu, izrazila i obrazložila svoj stav o kolonijalizmu. Pa ipak, možemo komentarisati izbor pojedinih reči koje bi odgovor učinile jasnijim i boljim.

Iz konteksta naslućujemo da je učenica umesto imenice detruiment (pravilan oblik le détriment na srpskom ima značenje šteta, uštrb) htela da upotrebi imenicu la destruction, što u srpskom znači uništenje, razaranje, od glagola détruire (što objašnjava i upotrebu prideva culturelle u ženskom rodu). Osim toga, zapažamo sintaksičku grešku kod konstrukcije glagola aider (ça aide au detruiment, a trebalo bi da glagol bude direktno prelazan ça aide le détriment//la destruction). $\mathrm{Na}$ kraju, umesto glagola avoir (les pays qui ont les colonies), smatramo da bi u ovom kontekstu bolje i preciznije rešenje bio glagol posséder.

Ispitanica sa $72,73 \%$ tačno rešenog testa i iz podgrupe „Ribnikar i časovi” je odgovorila:

Elle a des côtés positifs et negatifs, les colonies ont un interet économique pour l'Europe et il y a l'exploatation des culture, mais les population locales sont des fois mises à travailler par la force.

$\mathrm{U}$ navedenom odgovoru takođe vidimo jasno izražen podeljen stav kandidatkinje obrazložen sa tri argumenta.

Od grešaka najpre uočavamo sintaksičku grešku koja utiče na smisao rečenice. Naime, ukoliko eksploataciju poljoprivrednih kultura smatramo negativnom stranom kolonijalizma, kao i prisilan rad naroda u kolonijama, rastavni veznik mais trebalo bi da stoji ispred nezavisne rečenice il y a l'exploatation des culture, umesto sastavnog veznika et. Takođe, beležimo i pravopisne greške izostavljanje akcenata (negatifs umesto négatifs; interet umesto intérêt), kao i morfološke greške - slaganje imenica u množini (des culture umesto des cultures; les population umesto les populations). 
Još jedna učenica iz podgrupe „Ribnikar i časovi”, sa diplomom B2 iz francuskog jezika i 95,45\% tačnih odgovora, napisala je:

La colonisation a donné une avantage injuste aux métropoles, lorseque les indigénats et les autres pays devaient survivre avec leurs propres resources (ou sans des resources).

Za razliku od prethodnih odgovora, $u$ ovom primeru nisu korišćeni izrazi za izražavanje mišljenja. Ipak, $u$ odgovoru je učenica navela negativne strane kolonijalizma, te naslućujemo da je njeno mišljenje negativno. Osim toga, odgovor je jasan i precizan i leksički kvalitetan.

Od grešaka možemo izdvojiti morfološku grešku u rodu (une avantage, a treba un avantage) i dve ortografske greške (lorseque umesto lorsque i resources umesto ressources).

Na kraju, učenica iz podgrupe „Ostale škole”, sa 70,45\% tačnih odgovora je napisala:

Je pense que la colonisations a beaucoup aidé les grand pays, mais je ne vois pas la colonisation comme une chose pour être fier parce que beaucoup de gens sont maltraités. Je pense que c'est la negatif presentation du force.

Učenica je takođe jasno obrazložila svoj stav, ali uočavamo da u drugoj rečenici jezičke greške blago remete lako razumevanje odgovora.

Pre svega, uočavamo morfološke greške - pridev u množini (les grand pays, a treba les grands pays), pridev u ženskom rodu (la negatif presentation umesto négative), rod imenice (du force umesto de la force u ženskom rodu), broj imenice (la colonisations umesto colonisation, što je očigledno omaška, jer je u nastavku ista imenica u jednini tačno napisana). Osim morfoloških, primećujemo i sintaksičku grešku - redosled reči u rečenici (c'est la negatif presentation du force umesto c'est la présentation négative de la force). Najzad, u pridevu negatif postoji i pravopisna greška - nedostatak akcenta (negatif, a pravilno je négatif), kao i u imenici presentation (treba présentation).

$\mathrm{Na}$ osnovu odabranih, analiziranih odgovora, možemo zaključiti da su se ispitanici slobodno izražavali u svojim odgovorima, te da su na osnovu pročitanog teksta umeli da formiraju i izraze svoje mišljenje, što se od njih i tražilo. Sličnosti u kvalitetu odgovora prisutne su u primerima ispitanika različitih jezičkih profila. Odgovore su formulisali svojim rečima, ne oslanjajući se na originalan tekst. Prisustvo pravopisnih, morfoloških, sintaksičih i leksičkih grešaka u skladu je sa njihovim jezičkim nivoom ${ }^{6}$ i uglavnom ne ugrožava razumevanje iskaza. Prisustvo

${ }^{6}$ Od dvojezičnih učenika se očekuje da na kraju četvrtog razreda imaju jezičku kompetenciju najmanje na nivou B2, koja pruža mogućnost praćenja akademske nastave na stranim univerzitetima (Vučo 2009: 324; 2014: 142). Detalji u vezi sa deskriptorima za nivo B2 dostupni su preko sledeće reference: Conseil de l'Europe. (2001). Un Cadre européen commun de référence pour les langues: apprendre, enseigner, évaluer. Paris: Conseil de l'Europe/Les Éditions Didier. 
različitih i brojnih grešaka ukazuje da su učenici pre svega vodili računa o sadržaju, a manje o formi odgovora, kao i da nedosledno primenjuju jezička pravila.

U 10. zadatku otvorenog tipa, na delu testa vezanom za stručne termine, od učenika se tražilo da objasne dve imenice iz teksta. Ovo su njihovi tipični odgovori:

Métropole, n.f. (srp. država-matica u odnosu na kolonije)

- Les États Européennes (Grande Bretagne, France, Pays-Bas, etc.) qui gouvernent leurs territoires colonialles

- Les pays qui ont beaucoup d'influence sur des autres pays (leurs cité qui sont grand et ils s'expandent rapidement)

- Elle est representée par des fonctionnaires, gère directement la colonie

- Le pays qui a la colonie

Indigène, n.m. (srp. starosedelac)

- Une personne habitant la territoire colonialle, mais d'origine de cette territoire

- La population locale des colonie et les colonie en generale. Les pays qui ont besoin d'une ,missione civilisatrice“ ne sont pas civile au standard de les pays qui ont cet colonies

- Les indigénes sont les gens qui vivent aux pays colonials

U ovim primerima vidimo da je većina ispitanika davala objašnjenje termina u vidu definicija i oslanjajući se na kontekst imenica iz originalnog teksta, što jeste bio cilj zadatka. Tako su države-matice prikazane kao velike, uticajne sile, koje upravljaju kolonijama, dok je starosedelac definisan kao lokalna populacija, kolonizovan narod ili stanovnik kolonija.

Kao i u prethodnom zadatku, ovde uočavamo isti tip grešaka. Pravopisne (colonialles umesto coloniales; en generale umesto en général; missione umesto mission), morfološke - rod i broj imenica i prideva (qui sont grand umesto grands; leurs cité umesto cités; des colonie umesto colonies; cet colonies umesto ces colonies; les pays civile umesto civiles), oblik prideva u množini (colonials umesto coloniaux - hipergeneralizacija pravila o dodavanju slova ,,$"$ za množinu prideva), leksičke greške - (cité umesto villes, les gens qui vivent aux pays colonials umesto pays colonisés) i sintaksičke greške - sažimanje člana (de les pays umesto des pays).

I u primerima odgovora na ovo pitanje, vidimo da se kvalitet odgovora pre svega ogleda u njihovom sadržaju, dok su sa aspekta gramatičke kompetencije ispitanici zabeležili značajan broj grešaka.

Ovaj podatak možemo objasniti činjenicom da se tokom nastave nejezičkog predmeta od CLIL učenika pre svega traži tačnost u vezi sa sadržajem predmeta, dok je jezička tačnost u drugom planu. 


\section{ZAKLJUČAK}

$\mathrm{Na}$ osnovu rezultata prikazanih u ovom radu, ispitanici su u proseku tačno rešili $61,82 \%$ testa iz predmeta Istorija na francuskom jeziku, čime su ostvarili dovoljan uspeh, pri čemu je bilo 70,6\% ispitanika sa pozitivnim rezultatom (preko $50 \%$ tačno rešenog testa).

Ovi podaci pokazuju da je većina CLIL učenika četvrtog razreda Treće beogradske gimnazije i Desete gimnazije „Mihajlo Pupin” uspešno rešila test, te da ima razvijenu CALP kompetenciju iz oblasti istorije na francuskom jeziku, ali da je njihova kognitivno-akademska jezička sposobnost tek na dovoljnom nivou.

Ispitanici su više poena zabeležili na pitanjima u vezi sa pročitanim tekstom, nego na delu testa koji ispituje znanje iz leksike, što znači da su bolje savladali veštinu čitanja stručnog teksta iz ovog nejezičkog predmeta, nego vokabular iz ove oblasti.

Više poena na testu zabeležili su ispitanici koji imaju bolje jezičko znanje, koji su verovatno bili više motivisani za rad, a najuspešnija podgrupa bila je „Ostale škole i boravak".

Stoga, možemo zaključiti da CLIL nastava $u$ ove dve gimnazije ima pozitivan uticaj na razvijanje CALP kompetencije i da na taj način daje očekivane rezultate.

Sa druge strane, skroman, odnosno dovoljan nivo razvoja ove kompetencije možemo objasniti činjenicom da se u CLIL nastavi koriste domaći udžbenici, da učenici ne dobijaju dovoljno inputa na francuskom jeziku, kao i da nisu bili jednako motivisani za izradu testa (pojedini ispitanici su ostavljali nedovršene ili prazne odgovore kod otvorenog tipa pitanja).

$\mathrm{Na}$ kraju, u zadacima sa otvorenim odgovorom, većina ispitanika je pokazala da može jasno da izrazi svoje mišljenje i kvalitetno formuliše odgovor, uz česte pravopisne i morfološke, a ređe sintaksičke i leksičke greške, koje ipak ne dovode do nesporazuma.

Ovi podaci pokazuju da CLIL nastava od učenika na prvom mestu zahteva tačnost informacija vezanih za sadržaj nejezičkog predmeta, a tek onda doprinosi razvoju jezičke tačnosti i gramatičke kompetencije.

\section{LITERATURA}

Bourel, G., Chevallier, M.,et al. (2011). Histoire $1^{\text {re }}$ : Questions pour comprendre le $X X^{e}$ siècle. Paris: Hatier.

Coyle, D., Hood, F., Marsh, D. (2010). CLIL: Content and Language Integrated Learning. Cambridge University Press.

Cummins, J. (2008). "BICS and CALP: Empirical and Theoretical Status of the Distinction", in Encyclopedia of Language and Education, 2nd Edition, Volume 2: Literacy, ed. B. Street \& N. H. Hornberger (New York: Springer Science): $71-83$. 
Dale, L., Van der Es, W., Tanner, R. (2011). "CLIL Skills“. Preuzeto 9.3.2018. URL: $\quad$ https://www.epnuffic.nl/en/publications/find-a-publication/clilskills.pdf

Đurić, Lj. (2006). "Ogledi i inovativni projekti u nastavi francuskog jezika". Inovacije u nastavi 19: 28-40.

Ellis, R. (2003). Task-based Language Learning and Teaching. Oxford: Oxford University Press.

Filipović, J., Vučo, J., Đurić, Lj. (2007). "Critical review of language education policies in compulsory primary and secondary education in Serbia". Current Issues in Language Planning 8 (1): 222-242.

García, O. (2009). Bilingual Education in the 21st Century: A Global Perspective. Malden: John Wiley \& Sons Ltd.

Marsh, D. (2002). CLIL/EMILE - The European dimension: Actions, trends and foresight potential. University of Jyväskylä.

Petrović, E. (1988). Teorija nastave stranih jezika. Zagreb: Školska knjiga.

Pravilnik o bližim uslovima za ostvarivanje dvojezične nastave „Službeni glasnik RS”, br. 105/15. Preuzeto 2.2.2016. URL: http://www.mpn.gov.rs/wpcontent/uploads/2015/09/Правилник-о-ближим-условима-заостваривање-двојезичне-наставе-нови.pdf

Skutnab-Kangas, T. (1991). Bilingvizam da ili ne. Beograd: Zavod za udžbenike i nastavna sredstva.

Vučo, J. (2006). "U potrazi za sopstvenim modelom dvojezične nastave". Inovacije u nastavi 19: 41-54.

Vučo, J. (2007). "Jezici u formalnom obrazovanju u Srbiji", u Srpski jezik $i$ društvena kretanja (Kragujevac: Filološko-umetnički fakultet): 263-278.

Vučo, J. (2009). "Učiti na stranom jeziku - dvojezična nastava i jezik obrazovanja", u Jezik struke: teorija i praksa (Beograd: Čigoja štampa): 245-251.

Vučo, J. (2014). "Dvojezična nastava stranih jezika u Srbiji", u Jezici u obrazovanju i jezičke obrazovne politike, prir. J. Filipović \& O. Durbaba (Beograd: Filološki fakultet): 107-151.

Wolff, D. (2002). "On the importance of CLIL in the context of the debate on plurilingual education in the European Union", in CLIL/EMILE - The European dimension: Actions, trends and foresight potential, ed. D. Marsh (University of Jyväskylä): 47-48.

Zavišin, K. (2011). "Nastava italijanskog jezika u funkciji CLIL-a", u Jezik struke: izazovi $i$ perspektive: (Beograd: Društvo za strane jezike i književnosti Srbije): 732-740. 
Lidija P. Pasuljević Shimwell

University of Belgrade

Faculty of Philology

PhD Studies - Module Language

\title{
THE RESEARCH OF COGNITIVE ACADEMIC LANGUAGE PROFICIENCY OF STUDENTS INVOLVED IN THE FRENCH CLIL IN SERBIA: ANALYSIS OF RESULTS OF THE HISTORY TEST IN THE FRENCH LANGUAGE
}

\begin{abstract}
Summary
In the present paper we examine CLIL students' French language reading comprehension skills in History as a non-language subject. CLIL students are enrolled in bilingual education in Serbian as a native language and French as a foreign language. The main goal of our research is to determine whether the methods applied in the CLIL programme contribute to the development of students' Cognitive Academic Language Proficiency (CALP) in the French language. Fourth-year students of the Third Belgrade High School and the Tenth High School "Mihailo Pupin" participated in our study. Students were given a written test in History, which was divided in two parts - the first examining reading comprehension and the second tested the knowledge of specific vocabulary. The paper consists of five parts: Introduction, Foreign language acquisition in the CLIL programme, CLIL instruction in Serbia, Analysis of test results, and Conclusion. When analysing students' achievement in the test, we applied the qualitative-quantitative and descriptive methods. We also took into consideration the factors which may influence the test score besides the CLIL instruction (the length and type of French language learning that students were involved in). The test results show that CLIL students completed the test successfully since $70.6 \%$ of them marked over $50 \%$ of the correct answers, although the average score was 13.6 out of 22 points. In addition, students had $70.22 \%$ of the correct answers in the first set of questions, whereas their score in vocabulary tasks was $52.06 \%$. We conclude that the CLIL programme is effective and that students developed CALP, even though their Cognitive Academic Language Proficiency is at no higher level than the level of sufficiency.
\end{abstract}

Key words: bilingual education, CLIL, French Language, History, CALP, reading comprehension. 
PRILOG BR. 1: TEST IZ ISTORIJE NA FRANCUSKOM JEZIKU

\section{UN ÂGE D'OR COLONIAL?}

A.

Les empires sont le résultat d'un regroupement de territoires. La Grande-Bretagne regroupe 1'Inde, Ceylan et la Birmanie dans un Empire des Indes. La France crée l'Union indochinoise (Cochinchine, Annam, Cambodge, Laos et Tonkin). Les possessions africaines françaises sont regroupées dans l'Afrique occidentale française (AOF) en 1895, et l'Afrique équatoriale française (AEF) en 1910.

Les Européens adaptent le statut des territoires qu'ils dominent. On parle de l'administration indirecte quand les Européens se contentent d'encadrer les pouvoirs indigènes laissés en place. C'est le cas des protectorats français (Tunisie, Maroc, Annam, Laos), les colonies hollandaises et allemandes et la plupart des colonies britanniques. La Grande-Bretagne applique en effet une politique d'association ou de self-government. Entre 1867 et 1910, le Canada, l'Australie, la Nouvelle-Zélande et l'Afrique du Sud deviennent des dominions, États indépendants aux mains des colons d'origine européenne. Par l'administration directe, la métropole, représentée par des fonctionnaires, gère directement la colonie.

B.

L'opinion publique européenne est favorable à la colonisation. En 1931, l'exposition coloniale internationale de Paris accueille 33 millions de visiteurs. Elle présente les divers empires coloniaux, leurs cultures et l'étendue des réalisations européennes. Les zoos humains, expositions de villages indigènes «typiques », remportent un grand succès.

Les idéaux du colonialisme sont véhiculés par toute une imagerie qui glorifie la « mission civilisatrice » des métropoles et propose une vision stéréotypée et caricaturale de «l'indigène ».

Enjeu de puissance, les colonies ont un intérêt économique pour l'Europe. Elles sont de gigantesques fournisseurs de matières premières et offrent des débouchés aux industries métropolitaines.

La mise en valeur de ces territoires passe par le développement des infrastructures qui permettent les exportations. La part des échanges des métropoles avec leurs colonies est en constante augmentation : en 1938, 47\% des exportations britanniques se font vers l'empire, contre 22\% en 1913.

L'économie coloniale privilégie l'exploitation des matières premières (or, cuivre, phosphate...) et les cultures d'exportation (riz, coton, café, cacao...) et sacrifie les cultures vivrières.

C.

L'économie coloniale pèse lourdement sur les populations locales. Ces dernières voient leurs terres expropriées et sont parfois soumises au travail forcé dans des conditions terribles. 
À l'exemple de la France, plusieurs métropoles (Grande-Bretagne, Portugal, PaysBas) appliquent le régime de l'indigénat, généralisé à l'ensemble de l'empire colonial français en 1889, qui donne un statut légal inférieur aux populations indigènes.

(Bourel, G. (et al.). (2011). Histoire $1^{\text {re }}$ : Questions pour comprendre le $\mathrm{XX}^{\mathrm{e}}$ siècle. p. 250)

COMPRÉHENSION ÉCRITE

1. Quelles sont les thèmes clés abordés dans les parties $\mathrm{A}, \mathrm{B}, \mathrm{C}$ du texte? A-

B-

C-

Cochez la bonne réponse:

2. Le but de ce texte est de:

Informer le lecteur sur le colonialisme

Faire agir le lecteur

Justifier le colonialisme

Lutter contre le colonialisme

3. Le système colonial fin $\mathrm{XIX}^{\mathrm{e}}$ - début $\mathrm{XX}^{\mathrm{e}}$ était:

En déclin, touchant à sa fin

En pleine expansion

En crise

On ne sait pas

4. Pourquoi la population européenne soutenait-elle la politique coloniale?

5. Quelles sont les conséquences du colonialisme pour les populations colonisées?

6. Y avait-t-il un seul modèle de gouvernance? 
7. Quel est votre point de vue sur la colonisation? Expliquez.

\section{LEXIQUE}

\section{Choisissez la définition correcte des termes suivants: \\ 1. Colon ( $2^{\mathrm{e}}$ paragraphe) \\ Peuple, personne qui est sous le régime de la colonisation}

Groupe de personnes quittant leur pays pour aller en peupler un autre colonisation

Celui qui a quitté son pays pour aller occuper, cultiver une terre de

2. Dominion $\left(2^{\mathrm{e}}\right.$ paragraphe)

État autonome sur le plan de la politique intérieure, mais qui reste membre de l'Empire britannique

Action de dominer, d'exercer son autorité ou son influence sur le plan politique, moral, etc.

Qui fonde et exploite une colonie, qui transforme un pays en colonie

3. Indigénat (le dernier paragraphe)

Statut des indigènes qui les soumet à un régime juridique et fiscal d'infériorité et les prive des droits politiques

Territoire étranger placé sous la dépendance politique d'une métropole

Régime politique dans lequel le pouvoir est entre les mains d'un seul homme

9. Par quel synonyme pourriez-vous le mieux remplacer les mots suivants dans le texte (les mots sont soulignés dans le texte):

Encadrer

Organiser

Entourer

Garnir

Contenir

Débouché

Sortie

Écoulement

Débordement

Marché 


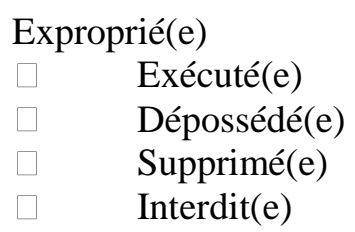

10. Expliquez les termes suivants (ils sont en gras dans le texte): Métropole, n.f.

Indigène, n.m.

Primljeno: 1. 5. 2018.

Prihvaćeno: 14. 8. 2018. 